Resumo

O artigo aborda a prdbemática da educaçãoa partir dedais dementos ensind aprendizagem e transmissãa Argumenta que a abordagem da eduração deve ser pensada a partir da nọão de autoridade e verifica, nessa diregãa opapd da transmissão na elucaçãa

Descritores: elucaçãa ensind/aprendizagem transmissãa, Fread; Lacan

\title{
EDUCAÇÃO: ENSINO OU TRANSMISSÃO?
}

\section{Cristia Rosineir Gonçaves Lopes Comea}

\section{A dimensã o da tra nsfe rênc ia c omo a mor a o sa berna educ açã o}

L acan, em uma fidelidade ética a Freud, afirma-se no seu campo, para contornar uma certa crise conceitual, que ocorreu dentro do meio psicanalítico na maneira pela qual os seus "seguidores" passaram a ler o fenômeno da transferência. 0 retorno a Sócrates por parte de Lacan (1992), ao Banquetede Platão que se constitui em um elogio ao amor, retorno feito no seu seminário sobre a transferência para situar o conceito de transferência em sua dimensão ética teve esse sentido: resgatar o que já estava marcado por Freud desde o estabelecimento da situação analítica. 0 analisante vem demandando uma ajuda, por um furo nas suas significações constitutivas e, por conseguinte, há uma demanda de saber suposto ao analista implicada nesse pedido de ajuda. A partir desse começo fundante, 0 analista é interrogado no lugar de quem sabe. Esse saber demandado diz respeito à verdade do seu desejo, que o analista supostamente detém.

Psic a na lista, Mestre em Filosofia e Étic a da Saúde Mental pela University of Warwick (UK). 
A partir da entrada de Alcibíades na casa de Agatão, onde Fedro, Pausânias, Erixímaco, Aristófanes, Agatão e Sócrates estavam reunidos para um elogio ao Amor, tudo muda, inclusive as regras antes instituídas. Alcibíades propõe, em lugar do elogio ao Amor, elogio ao outro, ao seu vizinho da direita. E Alcibíades faz, sem vergonha alguma uma confissão pública do que acontecera entre ele e Sócrates que já tinha sido seu amante. Alcibíades louva Sócrates, comparando-0 a uma imagem cujo exterior representava um sátiro ou um sileno, "divindades campestres, figuradas com cauda e cascos de boi ou de bode e rosto humano, singularmente feias, mas em que no seu interior havia uma outra coisa, coisa preciosa" (Platão, 1995, pp. 186-187).

Alcibíades avista agalmata em Sócrates e surge como efeito 0 amor. Agalma é um termo grego que pode ser traduzido por ornamento, tesouro. Embora, nesse momento, Lacan ainda não houvesse formulado o objeto a como tal, essa formulação só veio a acontecer no seminário da angústia (Lacan, 2005), a noção de agalma representa 0 ponto pivô da conceituação lacaniana do objeto causa do desejo (Kaufmann, 1996).

O desejo, no que visa a algo, acentua um objeto entre todos, privilegiando esse objeto, capturando 0 sujeito pelo acglma oculto nele. 0 desejo de Alcibíades se desencadeia na medida em que ele vê, em Sócrates, esse "tesouro inestimável que
Alcibíades proclama estar enterrado na caixa rústica que forma para ele a figura de Sócrates" (Lacan, 1998, p. 840) e, por isso, era preciso que Sócrates desse a Alcibíades o que lhe era suposto saber, o que Alcibíades tentara conseguir mediante uma solicitação de amor a Sócrates. Sócrates é solicitado por Alcibíades a responder no lugar de quem sabe o que causa o desejo.

Diante do pedido amoroso, Sócrates se posiciona recusando, porque sabe que não tem o que é procurado, o objeto faltante que causa 0 desejo; porque sabe tratar-se de uma armadilha esse harmonioso encontro, porque sabe quelhe falta, assim como falta a Alcibíades. Sócrates não realiza a metáfora do amor, já que "amar é dar o que não se tem” (Lacan, 1992, p. 157).

Se Sócrates assim se coloca diante da demanda de amor por parte de Alcibíades - onde você vê alguma coisa, eu nada sou - é porque ele sabe tratar-se de um vazio o seu ser. Alcibíades conclui o seu elogio, prevenindo Agatão a não se deixar enganar por Sócrates. Sócrates intervém, pontuando para Alcibíades que o que este falara não fora para ele, mas para Agatão. Sócrates assim aponta para além da sua pessoa.

D essa maneira, a partir da abordagem lacaniana, transferência é transferência de saber e, como efeito dela, surge 0 amor, amor ao saber. Mas, dado o caráter do amor como escamoteação do desejo, ela se apre- 
senta como resistência ao desejo como desejo do Outro. Estamos, portanto, diante do fechamento do inconsciente, da transferência em sua vertente de resistência como assinalou Freud em seus artigos sobre a técnica.

A abordagem lacaniana da transferência, como suposição de saber, tem 0 mérito de decantar a transferência como um dado estrutural do sujeito diante do Outro, e não como um fenômeno exclusivamente clínico - elemento já presente no texto do Freud. Isso introduz consequências para outros campos em que é sensível o lugar ocupado pelo Outro, como, por exemplo, o campo da educação, em que o professor é solicitado pelo aluno a responder no lugar de quem sabe.

É fato bastante evidente para qualquer um que tenha alguma experiência nesse campo que onde não há transferência, suposição de saber por parte do aluno no professor, não há aprendizagem, sugerindo ser a transferência uma condição para o processo ensino/ aprendizagem, tal qual a transferência é uma condição para um tratamento analítico. Poderíamos, então, reivindicar que, assim como a transferência veicula a possibilidade do tratamento analítico, ela veicularia a possibilidade do processo ensino/ aprendizagem? Em caso afirmativo, como a experiência o indica, como poderíamos entender a reivindicação de Freud (1937/ 1996b) em Análise temináve eintemináved, de que "a educação é impossível" (Freud, 1937/ 
1996b, p. 265)? Será que esse impossível a que Freud se refere na educação, assim como na análise, não deve ser pensado a partir do aspecto de resistência que a transferência, como vimos, comporta? No que, como efeito dessa suposição de saber surge 0 amor, 0 amor ao saber; e 0 amor, Lacan argumenta, comporta o caráter de escamoteação do desejo como desejo do Outro.

Millot (2001) argumenta que, embora a transferência esteja presente tanto no processo analítico como no processo educacional, os dois estariam radicalmente em direções opostas. Enquanto o processo educativo operaria com a transferência na mesma vertente que os pós-freudianos a conceberam, a saber, instituindo a dimensão do Ideal-do-eu presente na transferência, como motor do processo analítico e educativo, ou seja, tanto 0 analista quanto 0 educador operando e respondendo no lugar do Ideal; a especificidade da análise, a partir do rigor do espírito e da letra freudiana, sustentados por Lacan, tem por objeto a destruição da própria transferência, e por conseguinte, a queda do Ideal. O Ideal-do-eu é um dado de estrutura e, por isso, ineliminável da dimensão da transferência, seja ela no processo analítico ou educativo. A diferença, para Catherine Millot, está na posição que cada uma, psicanálise e educação, assume diante desse Ideal.

Com essa abordagem, Millot sugere que psicanálise e educação concernem a campos antagônicos, com direções radicalmente opostas, embora ambos, educador e analista, disponham desse poderoso instrumento que é a transferência.

Entretanto, como Millot bem observa, Freud (1925/ 1999) sugere a possibilidade de uma educação que se proponha ao mesmo objetivo que a psicanálise. Sugere que uma educação acabada, isto é, bem sucedida, deveria permitir a superação da dependência do sujeito para com as figuras parentais. 0 educador - bem como 0 analista - deveriam buscar a diluição do Ideal. Millot observa que essa outra direção na educação que Freud sugere está na contramão do narcisismo do educando, e pressupõe, por conseguinte, a aceitação da castração simbólica. O ra, consideramos esse pequeno contraponto em uma abordagem tão pessimista, no que concerne ao campo de articulação entre psicanálise e educação, como uma referência fundamental no que nos toca nesse artigo: Freud não nos dá, com isso, um indício de que e o processo educativo, tendo a transferência como mola-mestra assim como o tratamento analítico, pode operar sem ser necessariamente por uma via idealizante?

Santiago (2005) argumenta que a impossibilidade concernente ao ato de educar, reivindicado por Freud, qualifica apenas as modalidades do ato cujo efeito não se pode antecipar; e que é exatamente isso que ocorre no âmbito da educação. Diante da 
transmissão de um determinado conhecimento pelo professor para um grupo de alunos, uns aprendem, outros não. Lajonquière (1999) marca que toda educação pressupõe também a transmissão de um certo saber existencial que ultrapassa o conhecimento cognitivo.

Nessa direção, será que não poderíamos escutar, como consequência dessa reivindicação de Freud acerca do impossível da educação, que educação e ensino/ aprendizagem não são sinônimos? Que, enquanto o processo ensino/ aprendizagem é possibilitado pelo amor de transferência com a sua dimensão idealizante sem a sustentação do impossível que concerne à educação, 0 ato de educar requer a sustentação do impossível do real? Sustentação do impossível que funda algumas possibilidades e algumas contingências, como, por exemplo, o processo ensino/aprendizagem? E o que seria a educação, nesse registro do impossível? Pensamos que ela está articulada com a transmissão, dado que a transmissão, Freud (1939/ 1996c) em Maiséseomnotésmo reivindica ser a transmissão da castração. Com Lacan (1996a) sabemos que tal transmissão da castração concerne ao impossível do rell. Como a noção de transmissão, noção que privilegiaremos a partir de agora nesse artigo, está articulada tanto em Freud como em Lacan com a noção de autoridade, vamos à sua abordagem.

\section{Autorid a de, tra diçã o e e duc a çã o}

Hannah Arendt (2007) reivindica que a crise na educação é resultado direto da crise da autoridade deflagrada desde a época moderna. Segundo ela, a autoridade, tal como operou na antiguidade - a autoridade legítima que foi desenvolvida a partir da experiência da trindade romana de religião, tradição e autoridade e que foi entendida à luz da filosofia política grega - , foi perdida e degradada e não se restabeleceu em lugar nenhum.

Por se tratar de um mundo estranho para a criança, é necessário que 0 educador a introduza vagarosamente nesse mundo. Essa tarefa pertence ao campo da educação na própria medida em que o educador assume, em relação à criança e ao jovem, a posição de representante de um mundo pelo qual ele, o educador, deve assumir a responsabilidade implícita no fato de que os jovens são introduzidos por adultos em um mundo em contínua mudança. Essa respon- 
sabilidade pelo mundo assume a forma de autoridade. Como consequência, encontramos a degradação da autoridade no campo da educação, na medida em que a autoridade foi recusada pelos adultos. E isso somente pode significar uma coisa: que "os adultos se recusam a assumir a responsabilidade pelo mundo ao qual trouxeram as crianças" (Arendt, 2007, p. 240).

A crise da autoridade na educação guarda a mais estreita conexão com a crise da tradição, ou seja, com a crise de nossa atitude face ao âmbito do passado. A autoridade do mestre arraigava-se firmemente na autoridade inclusiva do passado enquanto tal. Tudo isso se põe em contradição com o nosso mundo atual, que não é mais estruturado pela autoridade, tampouco mantido coeso pela tradição. E o problema da educação no mundo moderno está no fato de, por sua natureza, não poder esta abrir mão nem da autoridade, nem da tradição e ser obrigada, apesar disso, a caminhar em um mundo que perdeu a ambas. A partir de Hannah Arendt, podemos dizer que essa é a problemática da educação: caminhar em um mundo que perdeu elementos dos quais sua natureza não pode abrir mão, a saber, a autoridade e a tradição.

Arendt reivindica que educar sem, ao mesmo tempo, ensinar não é possível, na própria medida em que "uma educação sem aprendizagem é vazia e, portanto, se degenera facil- mente. É muito fácil ensinar sem educar, e pode-se aprender continuamente sem que necessariamente seja educado" (Arendt, 2007, pp. 246-247). Em outras palavras, ela parece sugerir que, enquanto a aprendizagem é uma consequência natural, na qual a educação opera e que a educação consistente depende da aprendizagem como consequência; não necessariamente onde há aprendizagem a educação está operando, pois a primeira pode ocorrer sem a segunda.

\section{Autoridade - o que é tra nsmitid o: o sa ber ou a verdade?}

A construção do assassinato do pai da horda primeva feita por Freud (1913/ 1996a) em Totemetabu, fundamental para a abordagem do conceito de autoridade, é um mito e um mito é um saber sobre o impossível. Esse mito é um saber sobre a verdade do nosso desejo incestuoso e parricida, mas uma verdade impossível de dizer completamente no que ela concerne ao real; uma verdade "que se verifica por se guardar de ir até à confissão" (Lacan, 1996a, p. 126).

Embora Freud, em Tctemetabu, pareça sugerir em alguns pontos que o pai castrador era o pai vivo que impedia os filhos de gozar das mulheres por puro capricho e despotismo, ele por outro lado deixa-nos entrever que o pai castrador é o pai morto e assas- 
sinado, quando ele argumenta com um rigor impecável que o pai morto se torna mais forte que o fora vivo, na própria medida em que ao contrário da frase do velho pai Karamazov, "Se D eus está morto, então tudo é permitido", a conclusão que se impõe após a leitura do texto freudiano, que a frase referida consegue transmitir de maneira enxuta e tocante, é que Deusestámototem como resposta nada maisépemitida E Lacan, fiel ao espírito freudiano argumenta, então, que a castração, como o enunciado de uma interdição, só adveio quando do assassinato do pai, quando de um comum acordo entre os filhos em renunciar ao que motivou 0 assassinato.

Portanto, segundo Lacan (1996b) o operador estrutural é o pai morto que interdita o gozo, que tem o gozo sob sua guarda, que guarda o gozo como reserva, a saber, o pai assassinado de Totemetabu, que se situa para além do mito do Édipo. É do amor pelo pai morto, assassinado, que procede uma certa ordem.

Daí, podemos pensar que a autoridade concerne ao pai morto e assassinado. Que é somente a partir do estatuto de operador estrutural, de pai simbólico, que é justamente "o pai morto que só se alcança a partir de um lugar vazio e sem comunicação" (Lacan, 1996b, p. 90) que o lugar da autoridade se institui.

A descoberta freudiana do inconsciente anuncia que há uma verdade inconsciente do sujeito, desco- nhecida por ele por ser recalcada. A questão que surge disso é verificar em que medida 0 sujeito em análise poderia aceder a essa verdade por meio do saber particular que a análise lhe permite adquirir (Correa, 2005).

Com Lacan (1998), sabemos que a falta (de saber) constitui uma "fronteira sensível entre a verdade e o saber". "Fronteira sensível" introduz a dimensão da verdade não toda, na medida em que ela não cabe toda no campo do saber (Costa Moura, 2007, p. 21). Sabemos que a dificuldade encontrada por Freud, concernente aos limites da rememoração, se refere ao registro do real que Lacan (1975) afirma ser 0 isso de Freud e introduz, como impossível, o que nãopara denão se exeer. Para Lacan (1975), o real, tal como a psicanálise fala dele, é completamente desnudado de sentido. A psicanálise, por respeitar a ordem do impossível do real, não se submete ao ideal da palavra como o suporte da verdade cujo tradatuslóġo philosaphiasde Wittgenstein (1922) teve o mérito de deflagrar a contrapartida lógica desse ideal, a saber, a exclusão da dinâmica da verdade, a exclusão da falta de sentido (Correa, 2009). De acordo com Lacan (1996c), a verdade é certamente inseparável dos efeitos de linguagem tomados como tais, incluindo dessa maneira o inconsciente, tendo, portanto, a verdade, estrutura de ficção.

Dizer que a verdade tem estrutura de ficção é dizer que não há verdadeiro sem falso, pelo menos em seu 
princípio. No entanto, é falso reivindicar que não há falso sem verdadeiro, pois o verdadeiro não tem uma genealogia, remontando sempre a um primeiro verdadeiro do qual não poderia mais declinar (Lacan, 1996b). Incluir o inconsciente na dimensão da verdade como a psicanálise o faz, é reconhecer que a verdade é não toda. A verdade é não toda porque a linguagem, como Wittgenstein tanto enfatizou em Tradatus tem os seus limites. Esses limites, Lacan não deixa de reconhecer, mas, diferentemente de Wittgenstein, apesar dos limites, sustenta que é possível bordejar essa verdade que toca no impossível de ser dito (Correa, 2005).

No entanto, Lacan (1996b) também nos adverte contra a dimensão do amor à verdade, na medida em que essa dimensão não nos deixa entrever a impossibilidade do que se mantém como real, a saber, que a verdade só podemos semi-dizêla, advertindo-nos a não ir longe demais. Essa dimensão sustenta 0 poder dos impossíveis, a saber, "governar, educar, analisar eventualmente" (Lacan, 1996b, p. 179).

No seu seminário de 1973, Mais ainda, no capítulo intitulado " $\mathrm{O}$ Saber e a Verdade", Lacan traz duas reivindicações aparentemente conflitantes: de um lado, ele institui o Outro como o lugar do saber, o lugar onde o significante se coloca nos ofertando os indicadores de uma dimensão de verdade e que, por isso, "o estatuto do saber implica, como tal, que já há 
saber e no O utro, e que ele é a prender, a ser tomado. E por isso que ele é feito de aprendr" (Lacan, 1996a, p. 130). Entretanto, de outro lado, Lacan diz, no mesmo capítulo, um pouco mais adiante, que " 0 chato é que o O utro, o lugar, ele, não saiba nada" (Lacan, 1996a, p. 132). Como contornar esse embaraçoso aparente paradoxo?

No entanto, uma possível resposta parece se delinear, quando logo em seguida, Lacan aborda esse nada articulado com o ponto de falta no saber do O utro, ponto que toca no impossível do Real. Daí, então, é possível pensar que esse paradoxo é de fato apenas aparente, que o O utro castrado sabe, mas nada sabe da verdade do desejo da castração que concerne a um ponto opaco no seu saber.

Freud (1939/ 1996c) diz tratar-se, na transmissão da tradição de uma transmissão inconsciente, que com Lacan, a partir do seu comentário sobre a trilogia de Paul Claudel no seu seminário sobre a transferência, sabemos tratar-se de uma herança simbólica que concerne ao significante do desejo do Outro, significante da falta no O utro, que é transmitida entre gerações. Então, se o que é transmitido é a verdade da castração, verdade inconsciente que a tradição veicula, podemos dizer que o O utro nada sabe do que transmite?

Podemos dizer que esse é o estatuto da verdade a partir da descoberta freudiana do inconsciente: traumática, recalcada, que concerne à castração do sujeito e à do O utro. E é essa verdade que a tradição veicula, que é transmitida a partir de um lugar de autoridade. Então, se a verdade transmitida concerne à topada traumática com a castração no O utro, podemos pensar que a transmissão em jogo na autoridade é a transmissão de uma falta.

\section{A trilogia de Pa ul Cla udel e a herança simbólic a transmitida entre as gerações}

A trilogia "O refém", "O pão duro" e "O pai humilhado", a que Lacan em seu seminário sobre a transferência dedicou um comentário de quatro lições, traz no seu cerne o ponto que concerne ao pai enquanto autoridade.

Minimamente falando, trata-se, na primeira peça, em linhas gerais, de uma ação que visa a salvar o papa. A heroína dessa primeira peça, "O refém" (L'otage), é Sygne de Coûfontaine, uma personagem da aristocracia francesa visada e ameaçada, já que estamos 
nessa peça em plena revolução francesa. Além da aristocracia, a figura do papa como autoridade corria seríssimos riscos. Nesse cenário, Sygne de Coûfontaine é chantageada por Turelure e convencida pelo padre Curé Badilon, por meio de uma retórica perigosa e sedutora, a se sacrificar para salvar o papa cuja cabeça era visada. Ela decide, heroicamente, renunciar a toda dimensão do amor e se casar com Turelure, personagem descrito como repugnante, mas que, por ter ascendido com a revolução e gozar de poder e influência, poderia, caso ela se casasse com ele, poupar a vida do papa que parece ser o refém da peça. A peça termina com a morte trágica de Sygne de Coûfontaine, que deixa um filho tido com Turelure, não desejado por ela, Louis de Coûfontaine, cujo drama se desenrolará na segunda peça. No que toca ao nosso interesse aqui, o fundamental é ressaltar o desejo da heroína, Sygne de Coûfontaine, que adquire o estatuto de desejo puro por estar radicalmente desgarrado do circuito da demanda de amor. Por Sygne de Coûfontaine estar sustentada na radicalidade do seu desejo puro de salvar a autoridade ameaçada que o papa representa, o seu destino é trágico, pois sabemos com Lacan, desde o seu comentário sobre "Antígona" de Sófocles, no seu seminário A ética da psicanálise(Lacan, 1991), que, onde o desejo puro está operando, o horizonte é a morte.

Na segunda peça, "O pão duro" (Le pain dur), encontramos um complô contra Turelure, o pai de Louis de Coûfontaine, arquitetado pela amante de Turelure, Sichel, que vive com ele após a morte de Sygne, e por uma outra mulher com um certo envolvimento com Louis de Coûfontaine, Lumir, que consegue persuadir Louis a consentir com 0 plano. 0 Complô visa ao assassinato de Turelure para que Louis de Coûfontaine possa conseguir de volta tudo o que o seu pai paulatinamente lhe tirara. Louis de Coûfontaine é descrito como um homem endividado, que não consegue acesso ao usufruto, por seu pai tê-lo deixado sem nada devido ao olhar de desconfiança que o pai sempre teve para com ele. 0 seu pai, Turelure, não consegue aceder à posição de autoridade, de pai simbólico que funda o desejo, que por sua vez confere abertura em relação ao gozo. Turelure éum pai que se sustenta numa relação de rivalidade com o seu filho. Basta a ele perceber algo que o filho está investindo para ele desejar também esse objeto e competir com Louis. Turelure ocupa um lugar de pai obsceno que faz eco ao pai gozador da horda primitiva que se sente ameaçado por seus filhos, e por isso os expulsa de casa. O complô termina na morte de Turelure, mas ele não morre assassinado. Ele morre, na verdade, de susto diante da arma apontada para ele pelo filho. Turelure morre, literalmente, de medo e não pelo tiro de Louis, pois a arma de Louis falha. Com essa sutileza, Paul Claudel interdita o parricídio 
bruto. 0 pai morre, mas como um acidente de percurso. Com a morte do pai, Louis passa a ter acesso inclusive à amante do pai. Casa-se com Sichel.

No cerne dessa peça, está novamente a autoridade em jogo, a autoridade degradada que Turelure representa e a saída encontrada por Louis de Coûfontaine para ascender ao lugar de seu pai. A degradação da autoridade, nessa peça, coloca como saída relações sustentadas na identificação e na rivalidade.

A terceira peça, "O pai humilhado", trata de uma heroína, Pensée de Coûfontaine, filha de Louis de Coûfontaine e de Sichel. Segundo Lacan, essa terceira peça trata do desejo de Pensée de Coûfontaine, do desejo de pensamento, dado que pensée em francês significa pensamento. "E o desejo de Pensamento, vamos encontrar nele, certamente, 0 próprio pensamento do desejo" (Lacan, 1992, p. 293). Pensée é cega, e esse elemento nos parece significativo, na própria medida em que Lacan (1992) nos diz que o desejo é cego. 0 desejo é cego na própria medida em que na cegueira há o mínimo de imaginário e uma direção firme e precisa que arranca o sujeito da errância imaginária. Pensée sabe muito bem o que quer e, segundo Lacan (1992), ela "é uma figura incontestavelmente sedutora, que nos é manifestamente proposta, a nós, espectadores ... como 0 objeto do desejo" (p. 296). Ela aparece no baile de máscaras desfilando como se não fosse cega. "Pois sua surpreendente sensibilidade lhe permite, num instante de visita preliminar, observar, por sua fina percepção de ecos, de aproximações e de movimentos, toda a estrutura de um lugar, bastando para tal dar alguns passos" (p. 299), de tal maneira que durante todo um ato, aqueles que estão com ela poderão ignorar sua cegueira, especialmente Orian sobre o qual incidiu seu desejo. 0 desejo de Pensée tem uma direção firme e precisa: ela deseja não O rso, o bom rapaz que a ama, mas o dito O rian, que se apresenta como inacessível na sua santidade. "É um fato que o desejo nessa peça é mais forte que a própria santidade, e O rian, o santo, curva-se e cede no diálogo com Pensée, perde a partida" (Lacan, 1992, p. 301), e o sexo acontece entre os dois. " $\mathrm{E}$ é isso o que ela quer. $\mathrm{E}$ ao longo de todo 0 drama, ela não perdeu meio segundo, um quarto de linha, para operar nesse sentido pelas vias que não chamaremos as mais curtas, mas, certamente, as mais retas, as mais seguras" (Lacan, 1992, p. 301)

No final dessa terceira peça, Pensée, grávida de O rian, recebe a notícia de sua morte na guerra pelos lábios de Orso, que se compromete com ela a ser o pai de seu filho sem pretender jamais ser seu esposo. Orso diz a Pensée que a mensagem que $O$ rian lhe incumbiu de transmitir a ela é que é necessário viver. Pensée, diante da dor da perda do seu objeto de desejo, ao invés de sucumbir a essa 


\section{Artigo}

dor e cumprir um destino trágico, diz que não desistirá de viver, que perseverará no viver pela criança obscura, que nela é herdeira da alma dela e de O rian, que irá viver tanto quanto lhe for demandado. Por toda a vida, até o último minuto! Diz que não há como escapar da coragem de submeter-se a vida quando ela própria a estava sendo encarregada de dá-la a alguém.

No cerne dessa tragédia, está 0 desejo decidido e temperado de Pensée que prefere a vida à morte, por mais decepada que a vida possa ser $\mathrm{e}$ que diante do encontro com o real 0 toma como causa e persevera no viver. "Assim termina o projeto do poeta. Ele nos mostra, depois do drama dos sujeitos como puras vítimas do logs da linguagem, 0 que se torna 0 desejo" (Lacan, 1992, p. 303). 0 desejo poderoso de Sygne retorna na figura de Pensée como um desejo decidido e temperado.

\section{Disc ussã o}

O grande valor dessa tragédia, no que nos concerne aqui, toca primeiramente no que está no cerne dessa trilogia, que é a questão da autoridade. Essa trilogia se coloca na contramão da tendência deflagrada pela revolução francesa, que traz no seu cerne a degradação da autoridade. A revolução francesa deflagra a degradação do Nome-do-pai, no que rei- 
vindica o ideal da fraternidade no lugar da autoridade paterna. $\mathrm{Na}$ tragédia, trata-se de vigorar o simbólico dessa autoridade.

Além disso, o mérito dessa tragédia toca no que Lacan (1992) nos diz a respeito da herança simbólica entre as gerações a partir dessa trilogia, a saber, que três gerações bastam. Três gerações bastam para que o desejo puro de Sygne de Coûfontaine volte na figura de Pensée. Na primeira peça, há a incidência do significante, do significante do desejo do O utro, a saber, o desejo puro de Sygne de Coûfontaine. Na segunda peça, há a operação de recalcamento do significante do desejo do O utro, do significante da falta no O utro. E na terceira peça há o retorno do significante recalcado.

Chama-nos a atenção a afinidade entre a abordagem da herança transmitida entre as gerações feita por Freud em Maiśs eo montésm mesmo ele tendo falado nesse momento final de sua obra em herança atávica, denominação de que ele nunca abriu mão, e a abordagem da herança simbólica feita por Lacan a partir da trilogia de Claudel, fundamentada na abordagem freudiana do recalque que Freud colocou no cerne da transmissão da tradição a partir de um lugar de autoridade. Trata-se de um retorno do recalcado que passa a operar. Parece que, por mais que a ideia de herança atávica não tenha tido tempo para o seu declínio na obra de Freud em favor de uma herança simbólica, toda a estrutura da herança simbólica já estava no seu espírito e na sua letra. Com Lacan, podemos ler o suposto "biologismo" de Freud com o rigor devido, que a lógica do significante soube conferir a pontos como esse de sua obra, que estiveram ameaçados de perder seu vigor diante de interpretações biológicas compactas e pouco criativas.

Intrigante é que Lacan dedica quatro lições para abordar a herança simbólica, no seu seminário sobre a transferência, onde ele privilegia uma abordagem da transferência fundamentada no conceito de sujeito suposto saber, a partir do seu comentário do Banquatede Platão (1995) - especialmente, sobre a posição de Sócrates diante da demanda de amor feita por Alcebíades em direção a ele. Mas qual é a relação entre a transferência como suposição de saber no O utro e a transmissão simbólica que já podemos ver como a transmissão da castração? Qual a relação possível entre a transferência que pressupõe uma suposição de saber no Outro e a transmissão que pressupõe, por sua vez, que o O utro nada saiba da verdade que transmite? 0 objetivo desse artigo é abordar essa questão no campo da educação, pois, como marcamos na primeira parte 
desse artigo, uma consequência para a educação dessa abordagem da transferência como suposição de saber no O utro, é a transferência como condição para aprendizagem, ou seja, que exista por parte do aluno uma suposição de saber no professor. Em outras palavras, não haveria aprendizagem sem transferência.

Mas pensamos que Lacan, ao abordar de forma consistente (quatro lições não é um simples comentário) a transmissão simbólica entre gerações, no mesmo lugar onde o que está sendo privilegiado é a transferência como suposição de saber no $\mathrm{Ou}$ tro, nos dá um indício de que na transmissão, no que concerne ao campo da educação, por exemplo, estaria em jogo não somente a suposição de saber por parte do aluno no professor, como também a posição do professor diante do aluno operando como autoridade.

Reivindicamos, a partir do que foi abordado aqui nesse artigo, que esses dois operadores não estão indissociavelmenteligados, ou seja, na própria medida em que o aluno supõe saber no professor, não necessariamente por definição, o professor está no lugar de autoridade. Pensamos que Lacan nos dá o indício de que pode haver aprendizagem sem educação, mas não educação sem aprendizagem tal como Hannah Arendt reivindica.

Além disso, diferentemente do que Catherine Millot reivindicou não ser possível, uma articulação entre 
psicanálise e educação, por ser a educação uma prática a serviço do Ideal-do-eu, podemos reivindicar que, se o operador de uma prática é o Ideal, ela pode até ser chamada de processo de ensino/ aprendizagem, mas não de educação. Isto porque estamos argumentando aqui que o operador efetivo da educação, na contramão do que diz Catherine Millot sobre isso, concerne não ao Ideal-do-eu e sim à autoridade, pois o que está em jogo nela não é a abolição das diferenças a que visa o Ideal e sim a transmissão da castração. Embora comportando diferenças que escapam ao alcance desse artigo, a possibilidade de uma ética não de ideais, e sim pautada na transmissão da falta, marca com rigor que não se trata de dois campos antagônicos e sustenta a plausibilidade da articulação da psicanálise com a educação. Daí, podemos depreender um possível sentido para a reivindicação freudiana da educação como impossível. Embora Freud não tendo abordado o impossível do real da castração como Lacan 0 fez, podemos concluir que essa possibilidade de leitura do impossível da educação, sugerida nesse artigo, está em seu espírito e em sua letra.

Philippe Julien (2002), em seu texto Oamorpdopai emFreud, diz da única transmissão possível: a transmissão da falta. Só há herança na castração. É somente essa a herança que um filho pode esperar de um pai. Para isso, é preciso que esse pai seja e se saiba castrado e que possa, pela sua posição, se pôr a transmitir. Mais ainda, ele diz que Freud salva o pai e que é preciso ousar nessa questão e ir com Freud além de Freud, para que possamos avançar nesse ponto. A partir desse texto, a questão de ir além do pai é introduzida nas discussões sobre a transmissão, sugerindo que para haver transmissão é preciso ir além do pai e não salvá-lo (Pinheiro, 2007). De que se trata, nesse ir além do pai na transmissão que concerne ao campo da educação?

A transmissão na educação não se sustenta num saber todo e harmonioso, mas no não saber, no saber recalcado que toca no rel da verdade da castração e, por isso, no impossível que o educador e 0 aluno, ao se curvarem a ele, ao sustentarem a impossibilidade, fundam algumas possibilidades e algumas contingências

Enquanto o processo ensino/ aprendizagem ocorrido em função do amor de transferência com a sua dimensão idealizante sem a suntentação da impossibilidade concernente à transmissão mantém o sujeito numa relação de cola e de identificação, num fascínio e servidão ao mestre sedutor e detentor do saber, no ato de educar o 
que está em jogo é a transmissão. 0 que se transmite é o ponto de falta no saber. Não se sabe aprioi que está sendo transmitido algo. Só é possível saber da transmissão no campo da educação pelos seus efeitos, no depois, porque houve, na posição de professor um Outro castrado que transmitiu a sua falta. E será que podemos, a partir do texto de Philippe Julien, acrescentar: e por que houve na posição de aluno outro sujeito com a coragem de ir além e reinventar como herdeiro dessa falta - assim como Pensée na tragédia claudeliana colocou algo de seu no desejo puro herdado da avó, e pôde ir além da autoridade?

Entretanto, o que é privilegiado, nesse artigo, é que só é possivel ir além da autoridade do pai morto e aceder à originalidade, à invenção e ao estilo, ou seja, só há transmissão e, portanto, educação, se estivermos submetidos a essa autoridade.

EDUCATION: TEACHING OR TRANSMISSION?

Abst Ract

This artidedisausses thequestion of education from two elements, namely, teadhing learning and transmission The author posits that approading eduration ought to be thought from the notion of authority, and in this sense, treats of therdeplayed by transmission in education

Index terms: education; teading learning transmission; Freud; Lacan 


\section{EDUCACIÓN: ENSEÑANZA O TRANSMISTÓN?}

RESUMEN

El artíauloabordala austióndela eduracón a partir dedbsdementos la enseñanza/ aprendizaje y la transmisión. Sostienequed enfoquedela educacón debeser diseñado desded concepto de autoridad yanaliza, en esesentida \& papd dela transmisión en la educacoón

Palabras clave: eduración; ensenãrza/ aprendizaje transmisión; Freud; Lacan

\section{REFERÊNCIAS BIBLIOGRÁFICAS}

Arendt, H. (1954). Entreopassadbeofutura São Paulo: Editora Perspectiva, 2007. Claudel, P. (2005). L'dagesuivi deLepaindur edeLepèrehumilié Montreal: G allimard. Correa, C. R. G. L. (2005). Thelimits of langrage in philosquhy and in psychomalysis Dissertação de mestrado. University of Warwick, Coventry, UK.

A semântica de Frege e a dinâmica da verdade na psicanálise. Revista de Estudos Lacanianos, 4 (UFMG). (no prelo)

Costa-Moura, F. (2007). Sansão em cadeias: causalidade e significante na clínica psicanalítica. Pusional Revista dePsicanálise 20 (189), 17-26.

Freud, S. (1996 a). Totem e tabu. In S. Freud, Edição standard brasileira das daras psicoóǵcas completas de Sigmmd Freud (J. Salomão, trad., Vol. 13, pp. 333-345). Rio Janeiro: Imago. (Trabalho original publicado em 1913)

(1996 b). Análise terminável e interminável, 1937. In S. Freud, Edição standard brasileira das doras psicolóġas completas deSigmmd Freud(J. Salomão, trad., vol. 23, pp. 231-270). Rio de Janeiro: Imago. (Trabalho original publicado em 1937)

(1996c). Moisés e o monoteísmo, 1939 [1934-38]. In S. Freud, Edição standard brasilera das daras psicdógicas completas de Sigmmd Freud (J. Salomão, trad., vol. 23, pp. 19-150). Rio Janeiro: Imago. (Trabalho original publicado em 1939)

(1999). G eleitwort zu "VerwahrlosteJugend" von August Aichhorn, 1925.

E. Vidal, trad. Revista da Ledra Freudiana, 17 (23), 3-5.

Julien, P. (2002). O amor pelo pai em Freud. In P. Julien, Litoral: Do pai (pp. 171188). Rio de Janeiro: Companhia de Freud.

Kaufmann, P. (1996). Agalma. In P. K aufmann (O rg.), Dicionánio enidqpédico de psicanálise O leagado de Freud eLacan (pp. 15-18). Rio de Janeiro: Jorge Zahar.

Lacan, J. (1991). O seminánio livro 7: A ética da psicanálise, 1959-60 (A. Q uinet, trad.). Rio de Janeiro: Jorge Zahar.

(1992). O seminánio livro8: a transferênia, 1960-1961 (D. D. Estrada, trad.). Rio de Janeiro: Jorge Zahar.

(1996a). O seminánio livro 20: mais ainda, 1972-1973 (M. D. Magno, trad.). Rio de Janeiro: Jorge Zahar.

(1996b). O seminário livro17: oavessoda psicanálise 1969-1970(A. Roitman, trad.). Rio de Janeiro: Jorge Zahar.

(1996c). Conferênias e entrevistas nas Universidades Norteamericanas, 1975 (C. M. da Silva, trad.). Juiz de Fora: A to Freudiano Psicanálise Ensino e Transmissão. 
(1998). Subversão do sujeito e dialética do desejo no inconsciente freudiano, 1960. Escritos(V. Ribeiro, trad., pp. 807-842). Rio de Janeiro: Jorge Zahar.

(2005). O seminánio livro 10: a angís tia, 1962-1963(Vera Ribeiro, trad.). Rio de Janeiro: Jorge Zahar.

Lajonquière, L. (1992). Infândia e ilusão (psico)pedagógica: Escritos de psicanálise eedur caçãa Petrópolis: Vozes.

Millot, C. (2001). Freudantipedagogo Rio de Janeiro: Jorge Zahar.

Pinheiro, G. S. (2007). 0 pai ea transmissãa Revista do Ato Freudiano, 3 (2), 77-82.

Santiago, A. L. (2005). A inibiçãointdectual na psicanálise Rio de Janeiro: Jorge Zahar.

Platão. (1995). O banquete Rio de Janeiro: Bertrand Brasil.

Wittgenstein, L. (1974). Tradatus logico philosphiaus London: Routledge.

crlopes2001@yahoo.com.br

Reedidoemmaryol 2009.

Acitoemjulhd 2009. 